\title{
MITOS DE LA REFORMA LABORAL EN MÉXICO
}

\author{
Alejandro López Bolaños \\ Grupo de Análisis de Coyuntura de la Economía Mexicana \\ del IIE-UNAM
}

\begin{abstract}
En los últimos años, la reforma laboral, que permita formas más flexibles de contratación, ha sido presentada como condición necesaria para alentar el crecimiento económico y reducir el desempleo, además de incrementar la productividad empresarial, diversificar las oportunidades de empleo y aumentar la inversión extranjera.
\end{abstract}

\section{L} os alcances de la aprobación de la reforma laboral propuesta por el sector empresarial, los partidos políticos conservadores y algunos académicos ligados al statu quo sólo formalizaría la precarización del trabajo y las bajas remuneraciones, y daría garantías a los empresarios para agilizar el despido. En realidad, se trata de una contrarreforma laboral, que deroga las conquistas históricas de la clase trabajadora mexicana, mientras que facilita a los empresarios la apropiación del trabajo impago $\mathrm{y}$, con ello, el incremento de la tasa de beneficio.

\section{Mito 1: Una "nueva" ley laboral}

Desde la fundación del Consejo Coordinador Empresarial (CCE) en 1975, se consolidó una presencia política de los empresarios, quienes promovieron una reforma laboral a fin a sus intereses, proceso que se consolidó con la crisis de la deuda y los posteriores planes de ajuste, afianzando la presencia del sector empresarial en las decisiones de política económica, mientras que el sector obrero se sujetó a los intereses del partido gobernante, mismo que utilizó a las confederaciones obreras como un mecanismo institucional de control social ante las legitimas peticiones de los trabajadores.

Posteriormente, al inicio de la presidencia de Carlos Salinas de Gortari y con la promesa de alcanzar el Tratado de Libre Comercio de América del Norte (TLCAN), se propuso una reforma laboral acorde a los requerimientos de la clase empresarial. La globalización de la economía de mercado y de la producción, la modernización de los procesos productivos que implican la reducción de costos, la necesidad de proporcionar mayor confianza a los inversionistas, la elevación de la productividad y la calidad de los productos fueron los principales elementos discursivos utilizados por el CCE para promover el cambio en la legislación laboral en aras de alcanzar una mayor competitividad en la globalización. ${ }^{1}$

Rechazada por la Cámara de Diputados desde 1989, la reforma laboral salinista se impuso mediante la sustitución del salario integrado por bonos de productividad, lo cual repercute negativamente en las prestaciones y en la cotización de la jubilación, además de mantener una política de reducción salarial en aras de alcanzar la estabilidad de precios.
Durante su gestión como presidente de México, Ernesto Zedillo propuso la reforma laboral de 1998, la cual nuevamente fue rechazada, pero se aprueba la reforma a la ley del Instituto Mexicano del Seguro Social (IMSS), lo cual convierte en activos financieros privados a las pensiones de los trabajadores, de tal manera que sin modificar la ley laboral, se consigue la gran paradoja de que el sector obrero financie al gran capital financiero.

Durante el periodo 2000-2012, los gobiernos en turno han propuesto una reforma laboral que no opone límites al deterioro de las condiciones de trabajo. Sus principales propuestas son: sustituir los contratos de planta por trabajo eventual y por horas, lo cual es el extremo de la flexibilidad pues modifica en lo sustancial la estabilidad y permanencia en el empleo; facilitar y abaratar los despidos mediante la disminución de los salarios caídos, nuevos causales de rescisión y que el subcontratista sea el principal responsable de la relación entre los trabajadores y los patrones, es decir, darle legalidad a las prácticas ilegales que despojan de sus derechos esenciales a los trabajadores contratados vía el outsourcing. ${ }^{2}$

Recientemente, el CCE ha manifestado su deseo porque esta reforma sea aprobada, pero en lo esencial, la reforma ha avanzado paulatinamente desde 1989 y, en suma, de lo que se trata, es de darle carácter de ley a las prácticas utilizadas por el sector patronal, tratándose de un mercado laboral ya flexible donde la legislación laboral se transgrede ante el beneplácito de la Secretaría del Trabajo, encomendada a un representante de los empresarios.

\section{Mito 2: La reforma laboral estimularía el crecimiento, la inversión y el empleo}

Como se ha mencionado, la reforma laboral aún sin aprobarse en el Congreso, ha manifestado avances sustanciales , sin que ello haya logrado estimular el crecimiento, la inversión y la generación de empleos. En realidad, la reforma laboral y su resultante flexibilidad del trabajo no impulsaron el crecimiento económico y sólo han servido para agudizar la desigualdad social, particularmente en la disparidad del ingreso.

Las últimas tres décadas en México se caracterizan por el mediocre crecimiento de la economía, fragilidad 
financiera, crisis recurrentes que van más allá de lo económico-financiero y que abarcan al sector alimentario y a la seguridad pública, deterioro en la calidad de la educación, baja inversión pública y privada y la presencia de un creciente sector poblacional que ante la falta de empleos formales encuentra una fuente de ingresos en las actividades informales, e inclusive, en el crimen organizado.

El resultado más notorio del estancamiento económico y la disminución de la inversión, es la consolidación estructural del desempleo, un mercado laboral heterogéneo, con calidad deteriorada en los puestos de trabajo y que al adoptar formas flexibles de contratación de mano de obra fomenta la proliferación de empleos temporales, contratos de tiempo parcial y la progresiva reducción del salario. La información de la gráfica 1 demuestra que ante la caída en la tasa de inversión y el mediocre crecimiento económico, el desempleo ha aumentado, destacando los años de graves crisis como 1982, 1983,1995 y 2009, además de que desde 1995 y hasta 2011, en promedio se crean al año 400 mil empleos, una cifra alarmante para una economía que en el mismo periodo incorpora en promedio cada año a $1.2 \mathrm{mi}-$ llones de personas a la población económicamente activa.

La tasa de desocupación en 2011 fue de $5.2 \%$, muy superior a la de $3.6 \%$ de 2007 , cuando la crisis económica comenzó a tener repercusiones para la economía mexicana. ${ }^{3}$ En los últimos cinco años se registra un rezago potencial de 4.3 millones de puestos de empleo, los cuales se han cubierto con la migración hacia Estados Unidos, el empleo informal, la delincuencia y el crecimiento de los llamados "ninis".
Los jóvenes son los más golpeados por el desempleo, pues $66.0 \%$ labora en la informalidad, y $40 \%$ en empresas que no tienen seguridad social ni prestaciones. ${ }^{4} \mathrm{El}$ mayor nivel de desempleo se da entre los jóvenes con más años de estudio ( $71.2 \%$ del total de desempleados). La tasa de desempleo juvenil registró $12.7 \%$ en 2011, un nivel considerablemente superior a la tasa de desempleo total de la economía. ${ }^{5}$

En el 2011, la tasa de ocupación en el sector informal registró $28.8 \%$, en 2006 dicha tasa era de $27.0 \%$. Esto conduce a la reflexión, de que el problema del empleo no sólo corresponde a la cantidad sino también a su calidad, pues al cierre de 2011, 65.7\% de los empleados eran trabajadores formales, esto quiere decir que $34.3 \%$ de los subordinados a un patrón se ocupan en actividades informales. ${ }^{6}$

El Instituto Nacional de Estadística y Geografía (INEGI) considera población informal a todas aquellas personas que realizan actividades económicas de mercado que operan con recursos a partir de los hogares pero sin constituirse como empresas con una situación independiente de esos hogares. Definición limitada ante el creciente número de profesionales de diversas ramas que se emplean en contratos temporales, sin prestaciones o que realizan actividades de alta especialidad por cuenta propia. Una vez contabilizadas a estas personas, se estima que la población informal ascendía a 15.3 millones de trabajadores en 2010, dos millones más que las reportadas oficialmente por el INEGI.

En resumen, las modificaciones y el consecuente deterioro del mercado laboral no generan más inversiones ni mejores empleos.

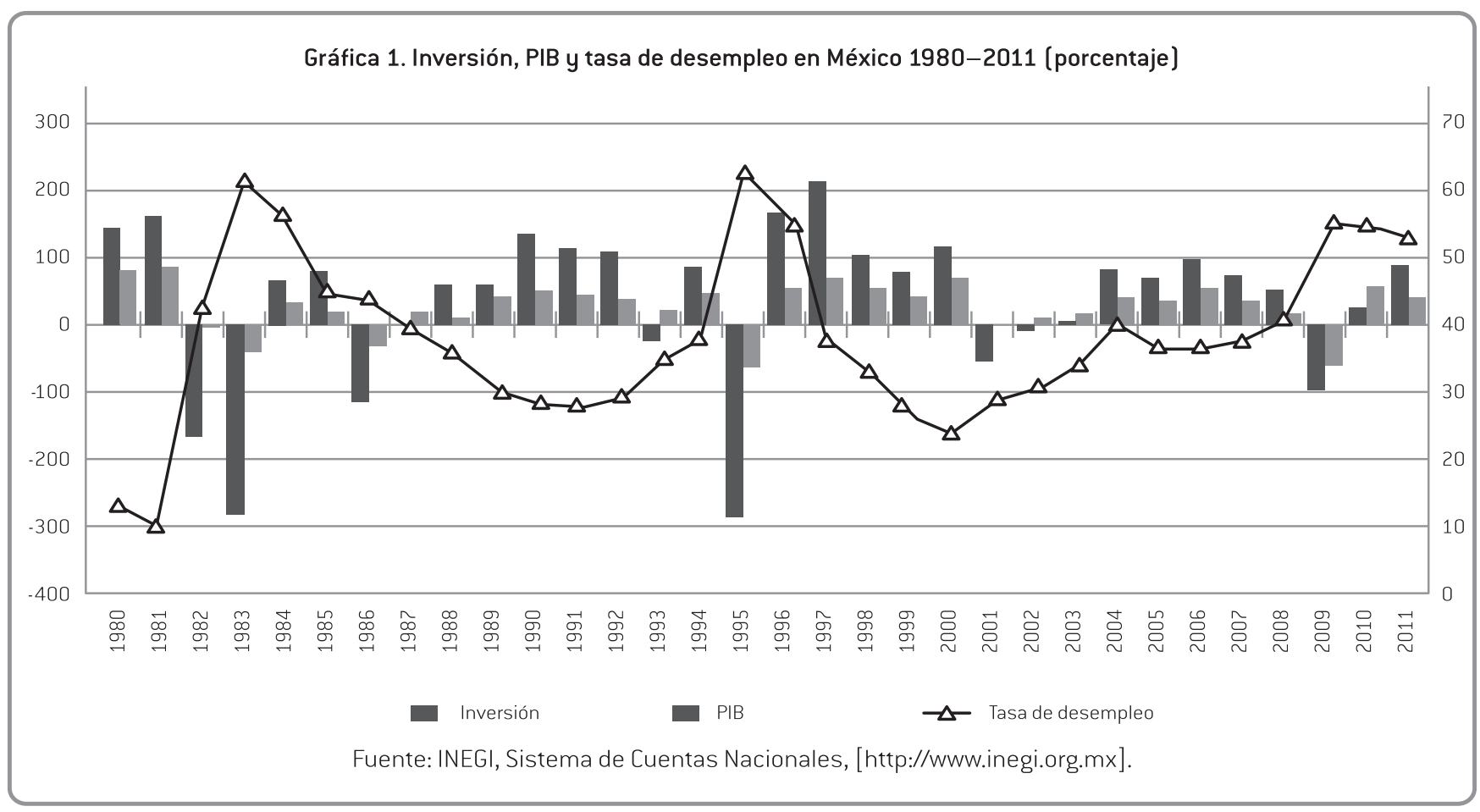




\section{Mito 3: La reforma laboral eleva la productividad y mejora los salarios}

Uno de los argumentos más utilizadas por el sector empresarial para exigir la aprobación de la reforma laboral es la necesaria elevación de la productividad, a partir de reducir los costos laborales, objetivo no cubierto y que, por el contrario, registra un severo retroceso, pese al grave deterioro en las condiciones de trabajo y de los salarios en México.

De acuerdo a la información proporcionada por la Organización para la Cooperación y Desarrollo Económico, ${ }^{7}$ la productividad en México creció $0.4 \%$ entre 1994 y 2010, variable que sirve al sector empresarial para exigir la reducción de los costos laborales, pues para ellos ésta es la causa de la baja productividad de la economía mexicana.

La reducción de los salarios ha reducido el costo laboral para las empresas sin que ello signifique mejoras sustanciales a la productividad. El crecimiento del costo laboral fue de $3.8 \%$ en 2010 , cuando en 2000 registró $11.2 \% .^{8}$

A consecuencia de esto, puede decirse que la baja productividad no es consecuencia de un aparente mercado laboral rígido que desincentiva la inversión, sino que el problema de la baja productividad recae en factores estructurales de la economía, tales como la arraigada heterogeneidad en las diversas ramas productivas, la fijación institucional del salario -es el único precio que se encuentra regulado-, alta informalidad en el mercado laboral, una configuración desigual en las fuentes de financiamiento acompañada de un sector financiero que ofrece créditos onerosos a las empresas, excesiva dependencia comercial con Estados Unidos, escasa investigación científica y tecnológica y la importación de bienes de consumo final y alimentarios que se han apoderado del mercado interno nacional y la informalidad.

El Banco de México considera que en el mercado laboral mexicano existen condiciones de holgura, como consecuencia de que "...tanto la tasa de desocupación, como la tasa de ocupación en el sector informal y la tasa de subocupación, permanecieron en niveles significativamente superiores a los observados antes del inicio de la crisis global, no obstante que el número de trabajadores asegurados en el IMSS mostró un elevado crecimiento". En congruencia con lo anterior, de acuerdo con la encuesta mensual de coyuntura del sector manufacturero, las empresas que constituyen dicho sector reportaron no haber enfrentado dificultades para contratar mano de obra calificada.

Estas condiciones de holgura se reflejaron en alzas salariales moderadas, lo que, junto con la tendencia positiva que mostró la productividad media del trabajo, contribuyó a que los costos unitarios de la mano de obra continuaran disminuyendo. Esto, a su vez, coadyuvó a que no se generaran presiones sobre los precios derivadas de las condiciones del mercado laboral". ${ }^{10}$

Para el banco central, los salarios son un costo que debe reducirse en concordancia con los objetivos de política monetaria. No debe perderse de vista que los salarios siguen

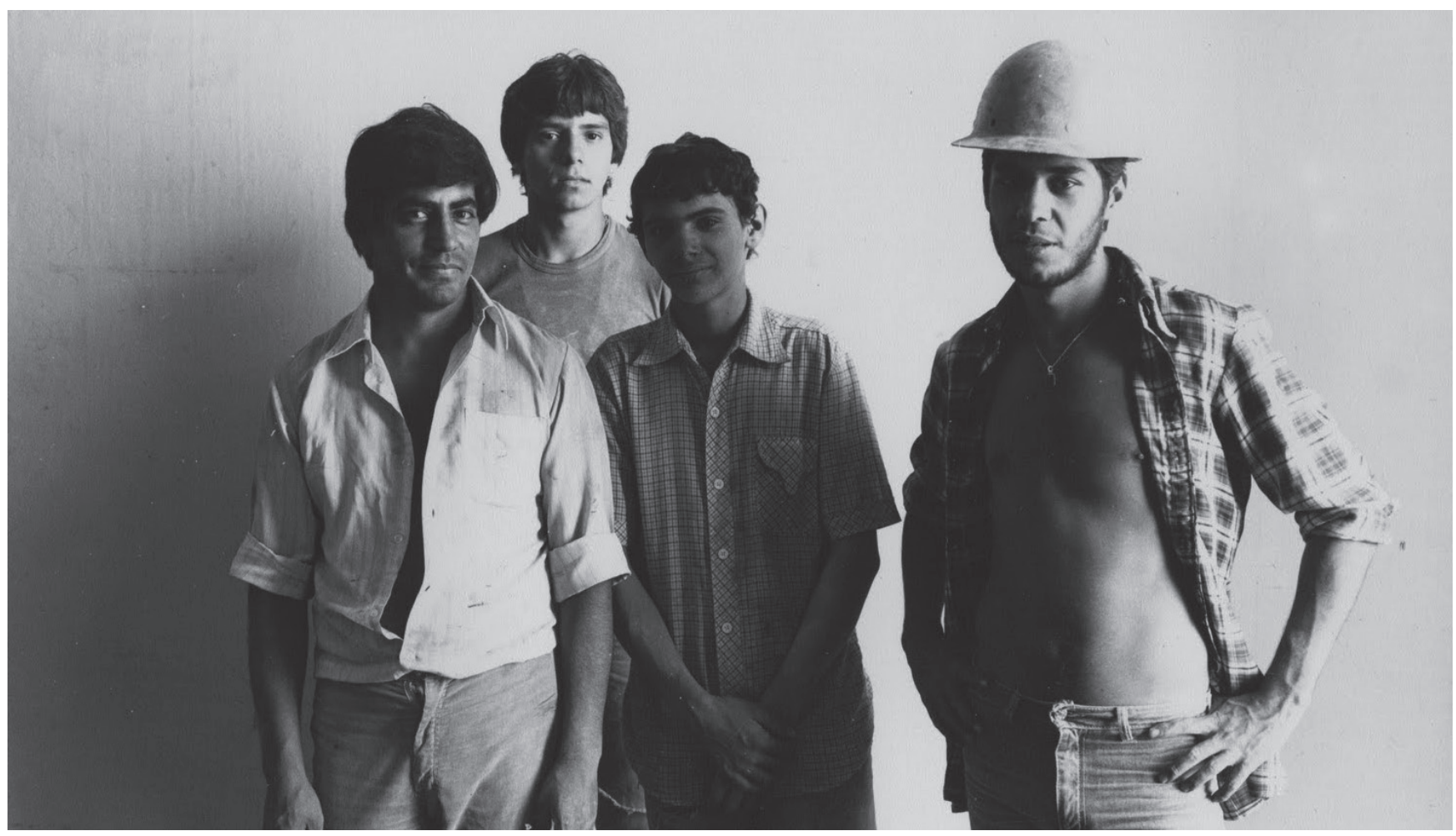


siendo un "mercancía" que mantiene un precio regulado, mientras se promueve a gran escala la desregulación de los precios de los demás bienes de la economía nacional, inclusive de aquellos elementales para el consumo alimenticio de la población (tortillas) y el de los energéticos.

La propuesta de reforma laboral pretende legalizar la superexplotación del trabajo, abaratando el valor de los trabajadores mientras persistan las estructuras precarias en el mercado laboral, las cuales reconoce y alienta el banco central llamándolas "condiciones de holgura", lo cual refleja el distanciamiento entre los objetivos de política monetaria y la política de crecimiento y generación de empleo que el país requiere.

Como consecuencia de esta política de reducción salarial, la tasa media anual de crecimiento de los salarios mínimos reales en el período neoliberal (1982-2012) es de $-3.8 \%$. Se calcula que desde 1978 , los salarios han perdido cerca de $75.0 \%$ de su poder adquisitivo, de acuerdo a las estimaciones realizas con base a los datos que proporciona la Comisión Nacional de Salarios Mínimos.

De los trabajadores ocupados, $13.0 \%$ recibían hasta un salario mínimo, $22.7 \%$ hasta dos, $21.1 \%$ hasta tres salarios mínimos, de tres a cinco salarios lo percibían $15.9 \%$ y más de cinco salarios mínimos mensuales $8.5 \%$. Tenemos que $56.8 \%$ de los ocupados percibe ingresos como máximo de tres salarios mínimos. Finalmente, $8.7 \%$ del total no percibe ingresos (dependientes no remunerados y trabajadores por cuenta propia en subsistencia) y había $10 \%$ de no especificado. ${ }^{11}$ Los trabajadores que ganan un salario menor a los 6 mil pesos, deben destinar más de $50 \%$ de los mismos a la adquisición de alimentos. Situación que se ha visto agravada en los últimos años por el alza internacional de algunos alimentos básicos.

\section{Conclusiones}

El crecimiento de la economía nacional, así como la disminución de la pobreza y de la tasa de desempleo, no se obtendrá con la aprobación de la reforma laboral. Resulta poco analítico afirmar que la aprobación formal de la reforma laboral neoliberal será el eje sobre el cual se supere la prolongada fase de estancamiento económico, pues en realidad la reforma ha registrado importantes avances. En realidad, el proyecto de reforma pretende subir a rango constitucional el carácter polarizante y excluyente del modelo económico vigente.

La reforma que el país requiere es aquélla que aplique realmente el contenido del artículo 123 de la Constitución, fundamentalmente, el derecho al empleo, a un salario digno y a la libertad sindical. Derechos sociales legítimamente ganados por los trabajadores, pero que el gran capital ha convertido en recursos mercantiles susceptibles de ser apropiados para convertirse en ganancias de los corporativos.
Referencias

1 Los puntos clave de la propuesta de reforma son los siguientes: 1) movilidad funcional y geográfica con multihabilidades; 2) contratos temporales, por hora o jornada reducida; 3) racionalizar causales de rescisión de contratos; 4) limitaciones en cuanto a responsabilidades en juicios laborales por el pago de salarios caídos; 5) pago por hora; 6) democratizar la huelga. Previo al estallamiento acreditar la voluntad mayoritaria de los trabajadores con voto secreto, asimismo en la decisión para levantarla; 7) desaparecer las juntas de conciliación y arbitraje; 8) desaparecer los contratos ley; 9) establecer contratos de capacitación sin que impliquen relación laboral; 10) acabar con el escalafón ciego y cambiarlo a escalafón por capacidad; 11) establecer prestaciones laborales y sindicales de acuerdo con las condiciones de cada empresa (implica el cuestionamiento del funcionamiento actual de la Seguridad Social); 12) eliminar la cláusula de exclusión por ingreso y separación; 13) libertad de sindicalizarse; 14) sindicalismo apolítico, es decir, acabar con la relación con los partidos (De la Garza, Enrique [2006], Restructuración productiva, empresas y trabajadores en México, México, Fondo de Cultura Económica/ UAM).

${ }^{2}$ Alzaga, Óscar (2012), "El despojo de los derechos del trabajo y la reforma laboral”, Momento Económico, no. 20, pp. 7-14.

${ }^{3}$ INEGI (2011), Encuesta Nacional de Ocupación y Empleo (ENOE), tercer trimestre de 2011, Aguascalientes, INEGI.

${ }^{4}$ OCDE (2011), Estudios económicos de la OCDE: México 2011, OECD Publishing (http://dx.doi.org/10.1787/9789264115934-es).

${ }^{5}$ Arancibia, Juan (2012), "El empleo, el ingreso y el actual gobierno”, Momento Económico, nos. 5-18, pp. 9-12.

${ }^{6}$ Ibidem.

${ }^{7}$ OCDE (2011), op cit.

${ }^{8}$ Ibidem.

${ }^{9}$ Banco de México (2012), Informe anual 2011, México, Banxico.

${ }^{10}$ Idem, pp. 18-19.

${ }^{11}$ INEGI (2011), op cit.. 